\title{
Le Subdray - Saint-Florent-sur-Cher - RN151
}

$\mathrm{n}^{\circ} 068500$

\section{Olivier Ranger et Multiple}

\section{(2) OpenEdition \\ 12 Journals}

Édition électronique

URL : http://journals.openedition.org/adlfi/13514

ISSN : 2114-0502

Éditeur

Ministère de la culture

Référence électronique

Olivier Ranger et Multiple, « Le Subdray - Saint-Florent-sur-Cher - RN151 », ADLFI. Archéologie de la

France - Informations [En ligne], Centre, mis en ligne le 10 octobre 2014, consulté le 01 mai 2019. URL : http://journals.openedition.org/adlfi/13514

Ce document a été généré automatiquement le 1 mai 2019.

(C) Ministère de la Culture et de la Communication, CNRS 


\section{Le Subdray - Saint-Florent-sur-Cher - RN151 \\ $n^{\circ} 068500$}

\section{Olivier Ranger et Multiple}

Code INSEE commune : 18255

Lien Atlas (MCC) : http://atlas.patrimoines.culture.fr/atlas/trunk/index.php?

ap_theme=DOM_2.01.02\&ap_bbox=2.268;46.986;2.340;47.051

1 L'opération d'évaluation archéologique localisée sur les communes de Saint-Florent-surCher et du Subdray (Cher) précède les travaux de mise à 4 voies de la route nationale 151 entre Bourges et Saint-Florent-sur-Cher par la Direction Départementale de l'Equipement $\mathrm{du}$ Cher. Le tracé totalise $3,5 \mathrm{~km}$, ce qui porte la surface à évaluer à 6,8 hectares. Environ $5,5 \mathrm{~km}$ linéaires de sondages ont été réalisés, soit environ $18 \%$ de la surface.

Les sondages archéologiques ont permis de mettre en évidence des structures en creux témoignant d'une occupation domestique des parcelles A283 et A726. Un trou de poteau est présent, mais en l'absence de grand décapage surfacique, aucun plan de bâtiment n'a pu être observé. Une fosse ainsi que 2 fossés sont présents. A l'exception du fossé 2023 qui a livré un vase attribué au $\mathrm{I}^{\mathrm{er}} \mathrm{III}^{\mathrm{e}}$ siècle apr. J.-C., aucun matériel archéologique n'a été récolté lors de la fouille des autres structures.

3 Une activité minière d'extraction de fer est décelable, puisque des puits, dont l'un débouche sur une galerie souterraine (non explorée pour des raisons de sécurité) ont été rencontrés. Une utilisation spécifique de l'espace est pressentie, puisque les puits sont concentrés et qu'aucune structure domestique n'est présente dans cette aire. 11 fossés parallèles ont été trouvés à proximité des puits, mais ils restent non datés, et n'ayant été dégagés que partiellement leur fonction reste imprécise. Il n'est pas exclu qu'ils soient liés à l'extraction minière (chemin d'évacuation du minerai ?). 
INDEX

Index géographique : Centre, Cher (18), Le Subdray, Saint-Florent-sur-Cher Mots-clés : vase, puits

operation Évaluation archéologique (EV)

Index chronologique : Ier siècle apr. J.-C., Gallo-romain 